\title{
The Transferability of a Candidate Reference Method for Determination of Creatinine in Serum
}

\author{
Louwerens Zwang', Bert G. Blijenberg', Henk Baadenhuijsen ${ }^{2}$, Bart A. J. van Landeghem ${ }^{3}$ and Johannes van Pelt ${ }^{4}$ \\ 1 Department of Clinical Chemistry, Academic Hospital Rotterdam-Dijkzigt, Rotterdam, The Netherlands \\ 1 Department of Clinical Chemistry, Academic Hospital, Nijmegen, The Netherlands \\ 3 Department of Clinical Chemistry and Haematology, St. Elisabeth Hospital, Tilburg, The Netherlands \\ 4 Department of Clinical Chemistry, St. Maartens Hospital, Venlo, The Netherlands
}

Summary: We developed a candidate reference method for the determination of creatinine in serum. For the acceptance of a reference method it is important that it be rigorously validated against a definitive method and that the method can be transferred from one laboratory to another.

This study focussed on the transferability and consisted of two parts: introduction and familiarization with the method in four clinical chemistry laboratories in the Netherlands, followed by independent measurements of Standard Reference Material 909a2 and several commercial quality control materials provided with reference method values according to the protocol of the German Quality Assessment Organisation.

The criterion for judging transferability was the mean total error (\%) of the five sera used in the accuracy experiment. For creatinine we used a total error of $<2.2 \%$. For Standard Reference Material 909a2 all four laboratories were able to comply with this demand, while only two laboratories met this requirement for the other four sera.

The results for the Standard Reference Material 909a2 from the collaborating laboratories demonstrate that this candidate reference method can be successfully transferred without loss of precision and accuracy.

\section{Introduction}

In earlier papers $Z$ wang et al. described various methodological aspects of a HPLC-based procedure for measuring creatinine in serum $(1,2)$. Since then, this selected method has been used in many clinical studies and for target setting of materials used in external quality assessment programmes.

During four years the stability of the method was assessed by using serum samples 909a1 and 909a2 (Standard Reference Material) obtained from the National Institute of Science and Technology (USA). In table 1 the results are given for the use of various columns and filters (batches, types), as well as the most recent results obtained with the same column and filter type.

The latter combination was also used in a limited comparison study with human serum samples using the definitive method of the Central Reference Institution of the German Society for Clinical Chemistry. The data are elaborated according to the statistical procedure described by Bland \& Altmann (3) and depicted in figure 1.

These favourable results prompted us to study the transferability of our method.

Transferability of a method implies that the method can be successfully applied in other laboratories based on specifications and procedures as described in the original method implementation.

Therefore three other Dutch laboratories, well experienced in routine high performance liquid chromatography (HPLC) determinations, were asked to evaluate interlaboratory transferability.

The transferability study was organized according to the guidelines of a multicentre study, i.e. with extensive

Tab. 1 Measurement of serum creatinine concentrations in SRM 909a1 and SRM 909a2 in laboratory A.

\begin{tabular}{|c|c|c|c|c|c|}
\hline & \multirow[t]{2}{*}{ Period } & \multirow[t]{2}{*}{$\mathrm{N}$} & \multicolumn{3}{|c|}{ Creatinine $(\mu \mathrm{mol} / \mathrm{l})$} \\
\hline & & & Mean & SD & $\begin{array}{l}\mathrm{CV} \\
(\%)\end{array}$ \\
\hline $\begin{array}{l}\text { SRM 909a la } \\
\text { SRM 909a2 }\end{array}$ & $\begin{array}{l}1991-’ 95 \\
1991-’ 95\end{array}$ & $\begin{array}{l}137 \\
167\end{array}$ & $\begin{array}{r}82.1 \\
458.9\end{array}$ & $\begin{array}{l}1.2 \\
5.9\end{array}$ & $\begin{array}{l}1.4 \\
1.3\end{array}$ \\
\hline $\begin{array}{l}\text { SRM 909a1 } \\
\text { SRM 909a2 }\end{array}$ & $\begin{array}{l}1994-’ 95 \\
1994-’ 95\end{array}$ & $\begin{array}{l}22 \\
52\end{array}$ & $\begin{array}{r}82.4 \\
464.7\end{array}$ & $\begin{array}{l}1.0 \\
3.7\end{array}$ & $\begin{array}{l}1.2 \\
0.8\end{array}$ \\
\hline
\end{tabular}

Remarks

a Experimental design changed from $15 \mathrm{~cm}$ columns to $5 \mathrm{~cm}$ columns with slightly modified ion-exchange material. Also the ultrafilters were from several manufacturers and the cut-off calues varied from $M_{\mathrm{r}} 10000$ to $M_{\mathrm{r}} 30000$.

b In this serics only the $5 \mathrm{~cm}$ ion-exchange colum was used together with the $M_{\mathrm{r}} 30000$ filter unit. 


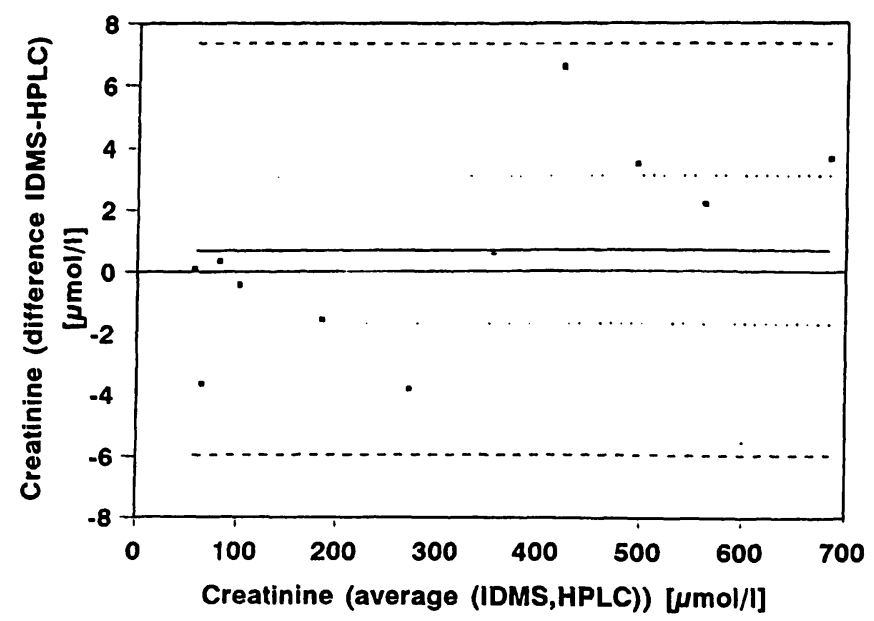

Fig. 1 Comparison of the method with isotope dilution-mass spectrometry (IDMS) for ten human sera. Mean difference 0.69 $\mu \mathrm{mol} / \mathrm{l}$, dashed lines 2 SD limits. Standard error of the mean 1.054 $\mu \mathrm{mol} / \mathrm{l}$, dotted lines $95 \%$ confidence interval S.E. M.

consideration of the methodological aspects beforehand, followed by an initial trial and finally a main trial (4). The Rotterdam laboratory was appointed as core laboratory.

\section{Materials and Methods}

\section{Materials}

Chemicals were essentially the same as in our previous study (1).

For calibration we used Standard Reference Material 914a from the National Institute of Standards and Technology (Gaithersburg, USA).

The stock solution of creatinine was prepared in class A glassware, in an approximate concentration of $5000 \mu \mathrm{mol} / \mathrm{l}$. In the initial trial, all laboratories used the same stock solution made by laboratory A. In the final study, all laboratories made their own stock solution. The stock solutions are used to prepare six aqueous standard solutions, all in class A glassware with class A volumetric pipettes, covering the range 50 to $1250 \mu \mathrm{mol} / \mathrm{h}$.

\section{Serum samples}

The weight of the water used for reconstitution of the lyophilized sera was taken to calculate the exact volume with correction for temperature and pressure. Sera and control material were divided into $1 \mathrm{ml}$ aliquots and stored at $-80^{\circ} \mathrm{C}$ until use. The frozen samples were distributed to the participating laboratories on dry-ice.

The following sera were used:

a. Testpoint Level 1, lots V8K501, V09316 (L1) and Level 2 lots V8K502, V09317 (L2) were unassayed chemistry control samples from Bayer Technicon, USA.

b. Human serum pools P1 and P2.

c. Standard Reference Material (SRM) 909al and 909a2, National Institute of Standards and Technology (Gaithersburg USA).

d. Serum samples as applied in the surveys organized by the Deutsche Gesellschaft für Klinische Chemie (Zentrale Referenzinstitution):

- Sample KL; Kontrollogen-L, lot no. 623134 Behringwerke AG, Marburg, Germany.

- Sample RV, serum sample used in a Germany survey.

- Samples PNU and PPU; Precinorm U, lot No. 182658 and Precipath U, lot No. 181801 Boehringer Mannheim, Mannheim, Germany.
In all German survey samples creatinine determinations werc performed by isotope dilution-mass spectrometry (IDMS) as described by Sickmann et al. and by a validated reference method (5-7).

\section{Methods}

\section{Ultrafiltration}

In this study Ultracent 30,000D (Bio-Rad Laboratories, Hercules, USA) was used instead of the Ultracent 10,000D. Ultracent $30,000 \mathrm{D}$ produces ultrafiltrate in a centrifuge with a swing-head rotor $(60 \mathrm{~min}$ at $2900 \mathrm{~g})$.

Adjustment for the volume displacement effect due to serum proteins was made according to Weast (8).

\section{Sample pretreatment}

Serum samples of $500 \mu \mathrm{l}$ were ultrafiltered for 60 minutes at $2900 \mathrm{~g}$, and $10 \mu \mathrm{l}$ aliquots of the ultrafiltrates were directly injected into the HPLC system. The ultrafiltrates were analysed in triplicate.

\section{Total protein determination}

Total protein was determined by a biuret procedure, calibrated against the reference method (9).

\section{High performance liquid chromatography (HPLC)}

All laboratories used the same $50 \times 4.6 \mathrm{~mm}$ (i.d.) modified weak cation-exchange column, column numbers 18056-18066, from Bio-Rad, Veenendaal, The Netherlands, as described by Zwang et al. (2). Columns were thermostated at $40^{\circ} \mathrm{C}$. The flow rates in the initial trial were 1.0 or $1.5 \mathrm{ml} / \mathrm{min}$; in the final experiments $1.0 \mathrm{ml} /$ min was chosen.

Participants applied their own HPLC-configurations.

- Laboratory A used the HPLC system as described in 1.c. (1).

- Laboratory B used a system of Hewlett Packard Co., Palo Alto, CA, model $1090 \mathrm{M}$ HPLC equipped with an ultraviolet diode-array detector.

- Laboratory C used a system of Thermo Separation Products, Fremont, California, USA, pump model AS 2000, autosampler AS 1000 and a Focus detector.

- laboratory D used a HPLC system of Bio-Rad, Hercules, California, USA, pump model 1330, autosampler model AS-100 and a Chrom-A-scope detector model 1970.

\section{Evaluation design}

The study started with a round robin in order to familiarize participants with the various technical aspects of the study. As a result we decided to perform an initial trial before the transferability study. All laboratories measured the linearity of this method on their own system, together with within-run and day-to-day imprecision study with two unassayed human serum samples and two control sera. The linearity test consisted of 6 aqueous dilutions of the creatinine stock $(50,100,250,500,750$ and $1250 \mu \mathrm{mol} / 1$ creatinine) and all concentrations were injected in triplicate.

In the main trial, day-to-day and within-run imprecision studies were repeated and accuracy was assessed. For the day-to-day imprecision the ultrafiltrates of four samples are measured in triplicate on ten working days. The within-run imprecision was determined on two levels by tenfold injections of two samples. For the accuracy study five validated reference sera and triplicate injection were used on three different days.

\section{Results}

\section{Evaluation of the initial trial results}

In the initial trial relatively high $\mathrm{CV}$ values, both between and within-run, were seen (tab. 2 and tab. 3). 
Participants were asked to examine their HPLC system carefully according to the following points:

- sample loop: two participants used a full loop and two a partially filled loop. For partial injection it is important that the syringe used in the autosampler is accurate. In the final trial only laboratory $B$ used partial filling.

- flow rate: flow rate was set to $1.0 \mathrm{ml} / \mathrm{min}$, as a lower flow rate increases peak areas (UV detectors are mass transfer-dependent). This is beneficial to the variation coefficient, especially at low concentrations of creatinine.

- detector: monitor the stability of the detector. The relatively short lifetime of a deuterium lamp (500$1000 \mathrm{~h}$ ) can cause changes in the peak areas due to fluctuations in the energy of the lamp when the lamp is due for replacement.

- integration parameters: peak areas were used and proper integration parameters should be used.

The linearity test performed well in all laboratories: all systems were linear up to $1250 \mu \mathrm{mol} / \mathrm{l}$ with a $r^{2}$ of at least 0.9999 . Because standard creatinine solutions are pure aqueous solutions, we decided to thoroughly exam- ine the performance of the ion exchange column. Differences seen during ultrafiltrate analysis were probably caused by unwanted coelution of a late eluting unknown component from a preceding injection. As all the participants used columns from the same batch we used a simple HPLC optimizing program, 'Emergo' (Chrompack, Bergen op Zoom, The Netherlands), to decide if optimization of the HPLC conditions for this batch was necessary. The result of this exercise was an increase of the lithium acetate concentration (from $15 \mathrm{mmol} / \mathrm{l}$ to 57.5 $\mathrm{mmol} / \mathrm{l})$ and an increase of the $\mathrm{pH}(4.8$ to 5.2$)$ of the elution buffer.

\section{Main trial}

All laboratories used samples L1 and L2 for determination of the within-run imprecision. The results are summarized in table 4.

For the day-to-day imprecision we also included Precipath $U$ and Precinorm $U$. The results are given in table 5. The last part consisted of the accuracy study with 5 validated serum samples. The numerical results of all measurements are mentioned in table 6 , while the total error data are graphically presented in figure 2.

Tab. 2 Initial trial day-to-day imprecision of duplicate filtrations measured on ten days in each of the four laboratories.

\begin{tabular}{|c|c|c|c|c|c|}
\hline \multirow[t]{2}{*}{ Sample } & & \multicolumn{4}{|c|}{ Laboratory } \\
\hline & & A & B & $\mathrm{C}$ & D \\
\hline $\mathrm{Ll}$ & $\begin{array}{l}\text { Creatinine }[\mu \mathrm{mol} / 1] \text {, mean } \\
\mathrm{CV}[\%]\end{array}$ & $\begin{array}{r}93.1 \\
0.8\end{array}$ & $\begin{array}{r}93.2 \\
2.4\end{array}$ & $\begin{array}{r}89.3 \\
2.7\end{array}$ & $\begin{array}{r}94.1 \\
3.8\end{array}$ \\
\hline L2 & $\begin{array}{l}\text { Creatinine }[\mu \mathrm{mol} / 1] \text {, mean } \\
\text { CV }[\%]\end{array}$ & $\begin{array}{r}628.7 \\
0.8\end{array}$ & $\begin{array}{r}618.7 \\
1.9\end{array}$ & $\begin{array}{r}604.0 \\
2.1\end{array}$ & $\begin{array}{r}637.2 \\
1.7\end{array}$ \\
\hline P1 & $\begin{array}{l}\text { Creatinine }[\mu \mathrm{mol} / \mathrm{l}] \text {, mean } \\
\mathrm{CV}[\%]\end{array}$ & $\begin{array}{r}115.1 \\
0.9\end{array}$ & $\begin{array}{r}114.1 \\
2.1\end{array}$ & $\begin{array}{r}109.1 \\
1.2\end{array}$ & $\begin{array}{r}116.5 \\
3.0\end{array}$ \\
\hline P2 & $\begin{array}{l}\text { Creatinine }[\mu \mathrm{mol} / 1] \text {, mean } \\
\mathrm{CV}[\%]\end{array}$ & $\begin{array}{r}414.2 \\
0.6\end{array}$ & $\begin{array}{r}408.3 \\
2.5\end{array}$ & $\begin{array}{r}393.3 \\
1.4\end{array}$ & $\begin{array}{r}419.1 \\
3.7\end{array}$ \\
\hline
\end{tabular}

Tab. 3 Initial trial within-run imprecision, with ten-fold filtration of all four samples, and HPLC analyses in triplicate.

\begin{tabular}{|c|c|c|c|c|c|}
\hline \multirow[t]{2}{*}{ Sample } & & \multicolumn{4}{|c|}{ Laboratory } \\
\hline & & A & B & $\mathrm{C}$ & $\mathrm{D}$ \\
\hline Ll & $\begin{array}{l}\text { Creatinine }[\mu \mathrm{mol} / 1] \text {, mean } \\
\mathrm{CV}[\%]\end{array}$ & $\begin{array}{r}92.0 \\
0.6\end{array}$ & $\begin{array}{r}94.0 \\
1.0\end{array}$ & $\begin{array}{r}89.3 \\
0.8\end{array}$ & $\begin{array}{r}93.6 \\
2.0\end{array}$ \\
\hline L2 & $\begin{array}{l}\text { Creatinine }[\mu \mathrm{mol} / 1] \text {, mean } \\
\mathrm{CV}[\%]\end{array}$ & $\begin{array}{r}627.0 \\
0.3\end{array}$ & $\begin{array}{r}621.8 \\
1.1\end{array}$ & $\begin{array}{r}597.3 \\
0.6\end{array}$ & $\begin{array}{r}629.4 \\
1.6\end{array}$ \\
\hline P1 & $\begin{array}{l}\text { Creatinine }[\mu \mathrm{mol} / 1] \text {, mean } \\
\mathrm{CV}[\%]\end{array}$ & $\begin{array}{r}115.1 \\
0.9\end{array}$ & $\begin{array}{r}116.5 \\
6.4\end{array}$ & $\begin{array}{r}107.4 \\
1.0\end{array}$ & a \\
\hline P2 & $\begin{array}{l}\text { Creatinine }[\mu \mathrm{mol} / \mathrm{l}] \text {, mean } \\
\mathrm{CV}[\%]\end{array}$ & $\begin{array}{r}415.8 \\
0.6\end{array}$ & $\begin{array}{r}403.9 \\
2.5\end{array}$ & $\begin{array}{r}393.3 \\
1.3\end{array}$ & a \\
\hline
\end{tabular}

a Due to a problem with a column oven laboratory $D$ produced no results. 
Tab. 4 Main trial of within-run imprecision, with triplicate filtration of L1 and L2, and ten HPLC analyses of the ultrafiltrates.

\begin{tabular}{|c|c|c|c|c|c|c|}
\hline \multirow[t]{2}{*}{ Sample } & & \multicolumn{5}{|c|}{ Laboratory } \\
\hline & & A & B & $\mathrm{C}$ & D & $\mathrm{All}^{\mathrm{a}}$ \\
\hline LI & $\begin{array}{l}\text { Creatinine }[\mu \mathrm{mol} / 1] \text {, mean } \\
\mathrm{CV}[\%]\end{array}$ & $\begin{array}{r}55.9 \\
0.3\end{array}$ & $\begin{array}{r}55.5 \\
0.6\end{array}$ & $\begin{array}{r}56.4 \\
0.5\end{array}$ & $\begin{array}{r}54.9 \\
6.5\end{array}$ & 55.7 \\
\hline L2 & $\begin{array}{l}\text { Creatinine }[\mu \mathrm{mol} / /] \text {, mean } \\
\text { CV }[\%]\end{array}$ & $\begin{array}{r}332.8 \\
0.5\end{array}$ & $\begin{array}{r}339.5 \\
0.3\end{array}$ & $\begin{array}{r}338.5 \\
1.1\end{array}$ & $\begin{array}{r}332.9 \\
2.7\end{array}$ & 335.9 \\
\hline
\end{tabular}

a Mean of means

Tab. 5 Main trial day-to-day imprecision measured on ten days, with single filtration and triplicate HPLC analyses on each filtrate.

\begin{tabular}{|c|c|c|c|c|c|c|}
\hline \multirow[t]{2}{*}{ Sample } & & \multicolumn{5}{|c|}{ Laboratory } \\
\hline & & A & B & $\mathrm{C}$ & $\mathrm{D}$ & $\mathrm{All}^{\mathrm{a}}$ \\
\hline Ll & $\begin{array}{l}\text { Creatinine }[\mu \mathrm{mol} / \mathrm{l}] \text {, mean } \\
\text { CV }[\%]\end{array}$ & $\begin{array}{r}56.3 \\
1.1\end{array}$ & $\begin{array}{r}55.5 \\
1.2\end{array}$ & $\begin{array}{r}56.0 \\
0.9\end{array}$ & $\begin{array}{r}56.2 \\
6.6\end{array}$ & 56.0 \\
\hline L2 & $\begin{array}{l}\text { Creatinine }[\mu \mathrm{mol} / 1] \text {, mean } \\
\text { CV }[\%]\end{array}$ & $\begin{array}{r}332.8 \\
0.4\end{array}$ & $\begin{array}{r}336.9 \\
1.1\end{array}$ & $\begin{array}{r}334.6 \\
1.3\end{array}$ & $\begin{array}{r}332.8 \\
1.8\end{array}$ & 334.3 \\
\hline PNU & $\begin{array}{l}\text { Creatinine }[\mu \mathrm{mol} / \mathrm{l}] \text {, mean } \\
\mathrm{CV}[\%]\end{array}$ & $\begin{array}{r}164.7 \\
0.8\end{array}$ & $\begin{array}{r}165.1 \\
0.5\end{array}$ & $\begin{array}{r}164.5 \\
1.0\end{array}$ & $\begin{array}{r}165.4 \\
2.7\end{array}$ & 164.9 \\
\hline PPU & $\begin{array}{l}\text { Creatinine }[\mu \mathrm{mol} / 1] \text {, mean } \\
\text { CV }[\%]\end{array}$ & $\begin{array}{r}353.2 \\
0.5\end{array}$ & $\begin{array}{r}356.0 \\
0.9\end{array}$ & $\begin{array}{r}352.6 \\
1.1\end{array}$ & $\begin{array}{r}352.3 \\
1.6\end{array}$ & 353.5 \\
\hline
\end{tabular}

a Mean of means

\section{Discussion}

The performance of a reference method in clinical chemistry implies high-quality analytical tools and personal dedication and skill $(10-12)$. Before the beginning of this creatinine transferability study, we were convinced of the existence of these preconditions in our group. Furthermore, we discussed the organization of the study at length and took many precautions. Despite all these considerations we failed in the initial trial, due to variation among the participating laboratories (tabs. 2 and 3). The modifications were applied, after discussions with all participants, proved to be successful as can be seen from tabs. 4 and 5.

The question arises as to whether we succeeded in upgrading the earlier published selected method to a reference method. Or in other words as raised by Moran: When is a "reference method" a "Reference Method" (13)?

An excellent review on the theoretical background of a reference method as a basis for accurate measuring systems is given by Büttner (11). Essential requirements in relation to the application of a reference method are described in this publication. The same holds in a practical way for a paper published by Thienpont et al. (14).

It is beyond the scope of our study to describe in detail all aspects related to reference methodology. High performance liquid chromatography is well ac- cepted for the determination of creatinine $(15,16)$. We intended to focus on an important element, i.e. transferability. This meant that we had to pay special attention to bias and imprecision. There are no strict internationally accepted rules regarding these aspects. Over the medically important range analytical goals for acceptance are: $1-3 \%$ for bias, $0.5-1.5 \%$ for within laboratory imprecision and $1-3 \%$ for between laboratory imprecision. In a recent discussion paper of a workgroup from the European Quality Assessment Organization a further specification is given based on the total error concept (14).

In this paper total error is defined as:

$$
\text { Total error }(\%)=\operatorname{Bias}(\%)+\frac{C V}{\sqrt{n}} \times t_{\alpha[n-1]} .
$$

For creatinine the following quality specifications are proposed: $t_{\alpha}=0.025$, bias $(\%)=0.6 \%$, imprecision $1.5 \%$ and total error $(\max ) 2.2 \$.$% .$

Our separate results in tables 4,5 and 6 present a very interesting picture. According to the Buittner cirteria, it is clear that all laboratories, except laboratory $\mathrm{D}$, attained the analytical goals. Application of the total error concept revealed that all laboratories were successful only with the SRM 909a2. For the other materials only laboratories $\mathrm{A}$ and $\mathrm{B}$ showed an adequate score. Most of the results show an acceptable imprecision (better than $1.5 \%$ ) for all participants, except sometimes laboratories 
Tab. 6 Summary of the five validated reference scra with respect to the Total error concept.

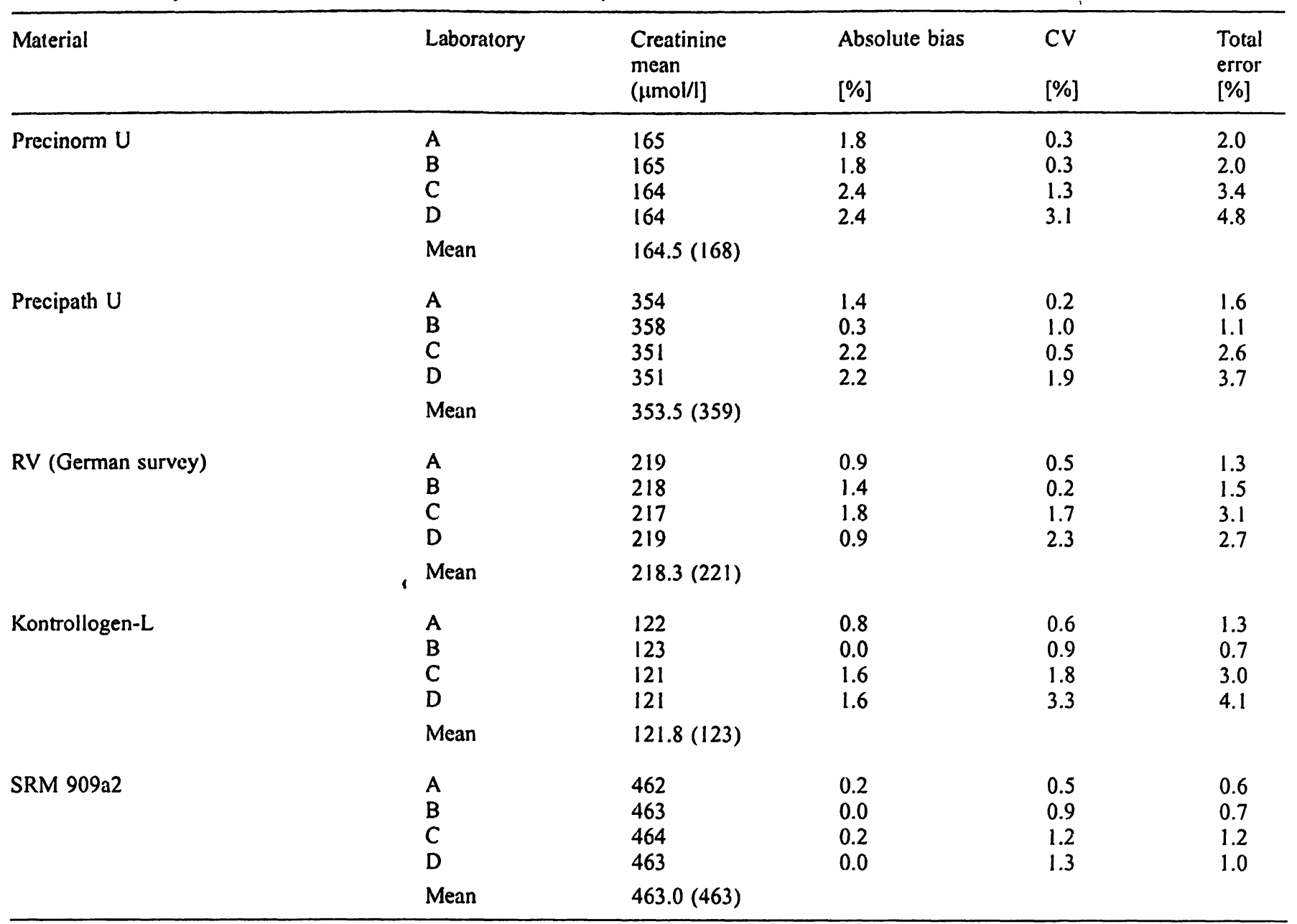

Remarks:

1. The column mean is based on 9 measurements.

$\mathrm{C}$ and $\mathrm{D}$, while in most cases the bias is higher than $0.6 \%$. This striking phenomenon leads to the question of the nature of the specimens used. As far as we know these were all human serum-based specimens. However, the commercial samples were normal manufacturer-produced quality control samples provided with reference method values according to rules of the German Quality Assessment Organisation (see Materials and Methods section part 2), while the SRM 909a2 was produced in

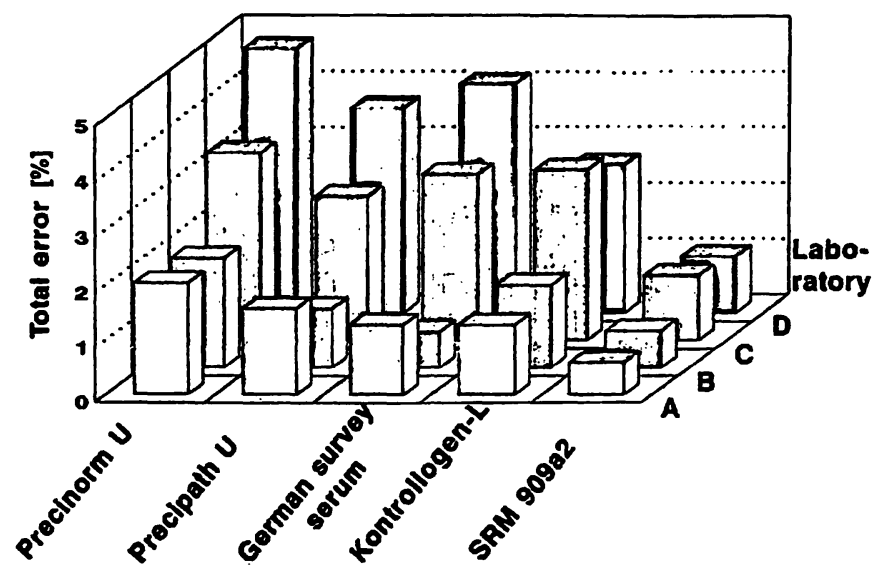

Fig. 2 Graphical presentation of the total error $\%$ of the five sera in relation to the four participants.
2. The row mean is the mean of all laboratories and is compared with the stated values between the brackets.

a limited batch at the highest technical level for application in very special purposes. We do not know whether or not this meagre information is sufficient to understand the discrepancies we found.

It stresses however once more the crucial importance of the required commutability of calibrating and/or control material. It seems to us that, as a matter of philosophy, the extent to which a reference method should, in all respects, be matrix robust. Certainly, a reference method has to be as specific and selective as possible. Should it also be able to selectively analyse totally unphysiological specimens? As long as questionable samples (and maybe the commercial samples we used belong to this category) are not included in a rigorous comparison study between a candidate reference method and an accepted definitive method, final answers to those questions cannot be given.

Summarizing all results of the main trial, we are of the opinion that our method shows good transferability. As expected, its application required much attention by the participants. We agree that, in particular for laboratory $D$, the imprecision needs improvement, although laboratory D did meet the quality specification with SRM 909a2. 
In this respect it is remarkable that the mean values for all specimens are so close together and particularly that the SRM 909a2 value is extremely correct.

From the results in table 1 , it can be seen that the SRM 909a2 results in particular differ from each other during the periods mentioned. During the years 19911995 we used a number of columns in combination with different types of ultrafilters while in the period 1994-1995 we applied the same combination as used in the transferability study, i.e. a $5 \mathrm{~cm}$ long cation exchange column and an ultrafilter with a cut-off value of $M_{\mathrm{r}} 30000$ both from Bio-Rad. It is clear from this example that for a proper choice of columns and ultrafilters, it is important to use samples like SRM 909al and 909a2.

\section{References}

1. Zwang L, Blijenberg BG. Assessment of a selected method for creatinine with a special emphasis on bilirubin interference. Eur J Clin Chem Clin Biochem 1991; 29:795-800.

2. Zwang L, Blijenberg BG. Validation of the ultrafiltration technique for the creatinine analyses by HPLC: a comparison with direct serum injection. Eur J Clin Chem Clin Biochem 1992; 30:861-6.

3. Bland JM, Altman DG. Statistical methods for assessing agreement between two methods of agreement. Lancet 1986; $\mathrm{i}: 307-10$.

4. Haeckel R, editor. Evaluation methods in laboratory medicine. Weinheim: VCH Verlagsgesellschaft $\mathrm{mbH}, 1993$.

5. Siekmann L. Determination of creatinine in human serum by isotope dilution mass spectroscopy. Definitive methods in clinical chemistry, IV. J Clin Chem Clin Biochem 1985; 3:137446.

6. Schumann G, Büttner J. A candidate reference method for creatinine with HPLC. Z Anal Chem 1986; 324:278-9.

7. Richtlinien der Bundesärztekammer. Deutsches Ärzteblatt 1988; 85:B519-32.

8. Weast RC, editor. Handbook of chemistry and physics, The Chemical Rubber Co., 18901 Crasewood Parkway, Cleveland, Ohio, 44128 55th ed. (1974-1975) D-221.

9. Doumas BT, Bayse Dd, Carter RJ, Peters Th, Schaffer R. A candidate reference method for the determination of total protein in serum, I development and validation. Clin Chem 1981; 27:1642-50.

10. Bowers HN. Clinical chemistry analyte reference systems based on true value. Clin Chem 1991; 37:1665-6.
In conclusion we are convinced, despite the limitations and incompleteness of the theoretical procedures, that we have succeeded in upgrading our selected method to a reference method.

\section{Acknowledgements}

We appreciate very much the cooperation of the following persons:

1. The technical staff of the participating laboratories for their dedication and skill in performing the HPLC analyses.

2. Miss $H$. J. Brouwer for her help in organizing all surveys and evaluation of all results.

3. Mr. G. H. Lubbers (Bio-Rad Laboratories B. V., Veenendaal, The Netherlands) for kindly donating the columns and ultrafilter units.

4. Prof. Dr. L. Siekmann (Institut für Klinische Biochemie der Universität Bonn, Bonn, Deutschland) for analysing the human serum samples used in this study.

11. Büttner J. Reference methods as a basis for accurate measuring systems. Eur J Clin Chem Clin Biochem 1991; 29:223-35.

12. National Committee for Clinical Laboratory Standards. Development of reference methods for the national reference system for the clinical laboratory; approved guideline. NCCLS Document NR SCL2-A. Vallanova, PA: NCCLS 1991.

13. Moran RF. When is a "reference method" a "reference method"? Clin Chem 1996; 42:112.

14. Thienpont L, Franzini C, Kractochvila J, Middle J, Ricos C, Siekmann L, Stöckl D. Analytical quality specifications for reference methods and operating specifications for networks of reference laboratories. Eur J Clin Chem Clin Biochem 1995; 33:949-57.

15. Büttner J. Reference materials and reference methods in laboratory medicine: a challenge to international cooperation. Eur $\mathrm{J}$ Clin Chem Clin Biochem 1994; 32:571-7.

16. Stöckl D, Franzini C, Kratochvila J, Middle J, Ricos C, Siekmann L, Thienpont LM. Analytical specifications of reference methods: compilation and critical discussion. Eur J Clin Chem Clin Biochem 1996; 34:319-37.

\section{Received June 3/August 16, 1996}

Corresponding author: Dr. Louwerens Zwang, Department of Clinical Chemistry, Academic Hospital Rotterdam-Dijkzigt, Dr. Molewaterplein 40, NL-3015 GD Rotterdam, The Netherlands 